\title{
MENINGOPATIA LEUCEMICA EM PACIENTE COM REMISSÃO HEMATOLÓGICA TRATADO COM SUCESSO PELO AMETHOPTERIN INTRATECAL
}

\author{
MÁrio RitTter * \\ Eliova Zukerman ** J. Baptista dos Reis**
}

A leucemia tem geralmente evolução avassaladora e deve sua alta morbilidade e inexorável mortalidade, não tanto à moléstia em si, porém ao grande número de complicações. Dentre as relativamente comuns e que muitas vêzes passam despercebidas estão as complicações neurológicas. Schwab e Weiss ${ }^{8}$ relataram a incidência de $20 \%$ de sinais e sintomas neurológicos em uma série de 334 casos de leucemia, reunidos em diversos hospitais de Boston. Nordlander ${ }^{5}$, numa casuística de 154 casos, verificou manifestaçōes neurológicas em $27(17,5 \%)$. Leidler e Russell 3 mencionaram uma incidência de $35 \%$ de manifestações neurológicas em um grupo de casos de leucemia escolhidos ao acaso. Wells e Silver ${ }^{12}$, com base no estudo de 63 casos, verificaram complicações neurológicas em 21. Shaw e col.10 observaram a ocorrência de 25 casos de meningopatia leucêmica em 150 pacientes $(16,7 \%)$. Um estudo amplo dêste problema foi relatado por Williams e col. ${ }^{14}$.

A complicação neurológica mais comum é a hemorragia intracraniana, conseqüente à diminuição acentuada do número de plaquetas; outra complicação freqüente é a infiltração leucêmica do sistema nervoso, central ou periférico; finalmente, existe um tipo de metaplasia leucêmica ao qual se pcde dar a denominação de meningopatia leucêmica. Estes diversos quadros de neuroleucemia podem se apresentar associados. As complicações neurológicas, de modo geral, podem aparecer nas leucemias em presença de alteraçōes hematológicas ou mesmo em fase de remissão das mesmas.

$O$ exame do líquido cefalorraqueano é valioso para o diagnóstico de neuroleucemia, pela verificação da presença de células leucêmicas, com ou sem pleocitose; em geral pode-se observar também hipertensão, aumento da taxa das proteinas totais e diminuição da taxa de glicose.

Trabalho apresentado ao Departamento de Hematologia e Hemoterapia da Associação Paulista de Medicina em 8-9-1964: *Assistente do Departamento de Clinica Médica (Secção de Hematologia) da Escola Paulista de Medicina; ** Assistentes do Departamento de Neurologia da Escola Paulista de Medicina. 
O tratamento por via intratecal desta complicação foi primeiramente utilizado por Sansone ?. Whiteside e col. ${ }^{13}$ fizeram experiências em cães para estudar a tolerância ao Amethopterin administrado por via intratecal; êles observaram também, em crianças, que a administração por via oral do medicamento não permitia obter nível terapêutico útil no líquido cefalorraqueano; ao contrário, a administração por via raqueana proporcionava níveis elevados por vários dias. Na literatura são escassas as comunicações a êsse respeito 1, 2, 4, 9, 11. Em nosso meio temos conhecimento apenas da comunicação do caso de Ramos $\mathrm{Jr}$. e col.6, no qual após várias tentativas terapêuticas sem sucesso, o uso do Amethopterin por via intratecal permitiu obter resultado imediato brilhante.

O relato do presente caso justifica-se não só pelo limitado conhecimento do assunto em nosso meio, como também pelo êxito terapêutico obtido.

C.H., branco, brasileiro, com 3 anos de idade, examinado em julho de 1962, com queixas de indisposição geral e dor de garganta, há uma semana. Ao exame físico, o paciente apresentava-se eutrófico, porém pálido, e com algumas manchas equimóticas nos membros inferiores; a temperatura axilar era de $38^{\circ} \mathrm{C}$; $\mathrm{o}$ cavo e as amigdalas estavam congestos e dolorosos à deglutição. O restante do exame clinico geral e neurológico foi normal. Exame hematológico: hemácias $2.950 .000 / \mathrm{mm}^{3}$; hemoglobina $7,5 \mathrm{~g} \%$; hematócrito $27 \%$; leucócitos $37.100 / \mathrm{mm}^{3}$ (mieloblastos e hemocitoblastos $82 \%$, linfócitos $15,5 \%$, neutrófilos $2,5 \%$ ); plaquetas $60.000 / \mathrm{mm}^{3}$. Com êsses elementos foi feito o diagnóstico de leucemia mielóide aguda. Como terapêutica foi usada 6-mercaptopurina associada a corticóides, sulfa de ação prolongada e transfusão sangüinea. Após 10 dias, o exame hematológico revelou melhora acentuada, tendo desaparecido as células blásticas e sendo menor a anemia; 20 dias após, o exame do sangue periférico mostrava-se normalizado, tendo o mielograma revelado hiperplasia granuloblástica com maturação normal, certo grau de gigantismo celular e raras células blásticas normais; os demais elementos da medula óssea não mostravam alteraçōes. Nesta ocasião o paciente apresentava-se clinicamente muito bem. Diante dêstes elementos ficou comprovada uma remissão clínica e hematológica do processo leucèmico.
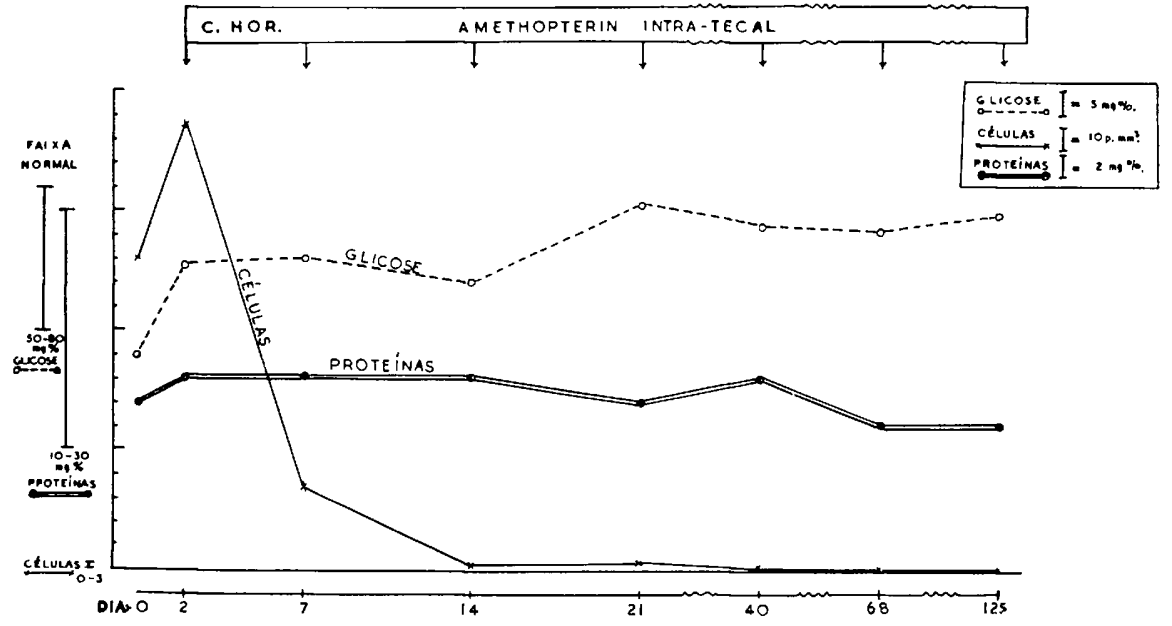

Caso C.H. - Gráfico da evolução das alterações do LCR após o inicio do tratamento. 
Esta situação manteve-se por 18 meses, quando surgiu a sintomatologia neurológica, caracterizada por vômitos, ligeira excitação psicomotora, cefaléia difusa e persistente. O exame clínico geral nada revelou de anormal. O exame neurológíco mostrou papiledema incipiente bilateral, ausência de sinais meningeos, não havendo sinais neurológicos focais. Para esclarecer êste quadro de hipertensão intracraniana foram feitos diversos exames subsidiários. O eletrencefalograma resultou normal. A radiografia de crânio revelou discreta disjunção das suturas, impressōes digitais mais intensas na parte posterior do crânio e sela túrcica sem alteracões. O exame do liquido cefalorraqueano (LCR) mostrou pleocitose de $130 \mathrm{cel} . / \mathrm{mm}^{3}$, na sua maioria absoluta constituída de células blásticas, discreta hipoglicorraquia, sendo os demais elementos normais. O sangue periférico e a medula óssea continuavam sem modificações. Como terapêutica foi utilizado o Amethopterin por via intratecal, na dose de $5 \mathrm{mg}$, repetida 6 vêzes, com intervalos de 5 a 7 dias inicialmente. A tolerância foi excelente, não tendo ocorrido qualquer reação secundária.

A evolução clínica foi muito boa. Observou-se o desaparecimento da cefaléia e vômitos logo após a primeira injeção intratecal, não mais reaparecendo ulteriorm€nte. Nova radiografia de crânio, feita dois meses após a primeira, já revelava redução das alteraçōes anteriormente verificadas. Exames de LCR foram repetidos em tôdas as amostras colhidas por ocasião das injeções intratecais, observando-se rápida e progressiva normalização do número de células e da taxa de glicose (gráfico). A percentagem de células blásticas, entretanto, diminuiu mais lentamente. Elas estavam presentes ainda quando o número global de células era normal, sòmente desaparecendo completamente após 2 meses de tratamento. $O$ paciente foi observado durante 4 meses com contrôle clinico e mediante exames de sangue e do LCR, permanecendo muito bem.

\section{SÜMULA E CONCLUSõES}

É apresentado um caso de meningopatia leucêmica com um quadro de hipertensão intracraniana, que surgiu 18 meses após a remissão clínica e hematológica de leucemia aguda. A terapêutica por via intratecal com o Amethopterin, na dose de $5 \mathrm{mg}$, repetida 6 vêzes e com intervalos de 5 a 7 dias, proporcionou melhora clínica imediata e normalização do LCR após dois meses de tratamento. O paciente continuou bem clinicamente e com o sangue e o LCR normais após 4 meses de observação. A experiência dêste caso e daqueles citados na literatura justificam que todos os pacientes leucêmicos sejam cuidadosamente observados a fim de se poder diagnosticar precocemente uma complicação neurológica, para que o tratamento adequado possa permitir maior sobrevida. O exame do LCR tem importância decisiva no diagnóstico desta complicação; ulteriormente, os exames seriados do LCR orientam a duração e a intensidade do tratamento. A padronização do tratamento das complicações neurológicas das leucemias constitui campo aberto às investigações.

\section{SUMMARY}

Meningeal leukemia occurring in a patient with clinical and hematological remission successfully treated with intrathecal Amethopterin.

The case of a 3-year old boy affected by acute leukemia and presenting a picture of meningeal involvement is discussed. The neurological ma- 
nifestations occurred after a period of 18 months of clinical and hematological remission. The symptoms were those of intracranial hypertension; presence of numerous leukemic cells in the cerebrospinal fluid and widening of cranial sutures were observed. A two months course of treatment with intrathecal injection of $5 \mathrm{mg}$ Amethopterin each brought about an excellent neurological recovery that is lasting for more than 4 months. The injections were made firstly at a five day interval, which was increased at the end of the treatment. The experience of this case added to those of prior cases documented in the literature stresses the importance of the problem. It is suggested that every case of leukemia be thoroughly examined and if symptoms and signs of neurological involvement were found, cerebrospinal fluid examination must be performed. Thus acting it will be possible to diagnose nervous system involvement and start the treatment at earlier stages. In this way the patient may have a better and longer life. The graph clearly shows the importance of cerebrospinal fluid examinations to evaluate the results of the treatment.

\section{REFERENCIAS}

1. HYMAN, C. B.; BRUBAKER, C. A.; BORDA, C. E.; HAMMOND, D. \& STURGEON, P. - Treatment of central nervous system leukemia in children. Proc. Am. A. Cancer Research 3:29, 1959. 2. LAURANCE, B. M. - Intracranial complications of leukemia treated with intrathecal Amethopterin. Arch. Dis. Childh., 36:107, 1961. 3. LEIDLER, F. \& RUSSELL, W. O. - The brain in leukemia. Arch. Path., 40:14, 1945. 4. MURPHY, M. L. - Leukemia and lymphoma in children. Pediat. Clin. N. Amer., 6:611, 1959. 5. NORDLANDER, N. B. - Eosinophilic leukemia; infiltration of the gasserian ganglion. Acta Med. Scandinav., 139:146, 1951. 6. RAMOS Jr., J.; De BELLIS, N. \& REIS, J. B. - Localização neurológica da leucemia aguda; estudo sôbre um caso e valor terapêutico do Amethopterin por via intratecal. II Simpósio de Quimioterapia Antineoplásica, Belo Horizonte, julho de 1963. 7. SANSONE, G. - Pathomorphosis of acute infantile leukaemia treated with modern therapeutic agents; "meningoleukaemia" and Frölich's obesity. Ann. Paediat., 183:33, 1954. 8. SCHWAB, R. S. \& WEISS, S. - Neurologic aspects of leukemia. Am. J. Med. Sc., 189:766, 1935. 9. SHANBROM, E.; MILlER, S. \& FAIRBANKS, V. F. - Intrathecal administration of Amethopterin in leukemic encephalopathy of young adults. New England J. Med., 265:169, 1961. 10. SHAW, R. K.; MOORE, E. W.; FREIREICH, E. J. \& THOMAS, L. B. - Meningeal leukemia: a syndrome resulting from increased intracranial pressure in patients with acute leukemia. Neurology 10:823, 1960. 11. SULLIVAN, M. P. - Intracranial complications of leukemia in children. Pediatrics 20:757, 1957, 12. WELLS, C. E. \& SILVER, R. T. The neurologic manifestations of the acute leukemias: a clinical study. Ann. Intern. Med., 46:439, 1957. 13. WHITESIDE, J. A.; PHILIPS, F. S.; DARGEON, H. W. \& BURCHENAL, J. H. - Intrathecal Amethopterin in neurological manifestations of leukemia. Arch. Int. Med., 101:279, 1958. 14. WILliAMS, H. M.; DIAMOND, H. D.; CRAVER, L. F. \& PARSONS, H. - Neurological Complications or Lymphoma and Leukemias. Charles C. Thomas, Springfield (Illinois), 1959.

Caixa Postal 5496 - Süo Paulo, SP - Brasil. 